\title{
Comparison of the diagnostic value of bone marrow biopsy and bone marrow aspiration in neoplastic disease
}

\author{
JAMES D. BEARDEN, GARY A. RATKIN, AND CHARLES A. COLTMAN \\ From the Hematology-Oncology Service, Department of Medicine, Wilford Hall USAF Medical Center, \\ San Antonio, Texas
}

SYNOPSIS The Jamshidi-Swaim biopsy needle was utilized to perform 205 bone marrow biopsies, accompanied by simultaneous bone marrow aspirates, on patients with lymphoma, leukaemia, and a variety of solid tumours. There was no significant morbidity. There were 67 positive findings with biopsy and 42 with aspiration. The two techniques were complementary in Hodgkin's disease, nonHodgkin's lymphoma, breast carcinoma, bronchogenic carcinoma, malignant melanoma, and in leukaemia. We have examined the bone marrow biopsies and aspirates with respect to the adequacy of the bone marrow biopsy specimen, the number of positive biopsies in the various categories of neoplasia, and the disparity of biopsy and aspirate, finding that 28 of the 67 positive biopsies $(41 \cdot 8 \%)$ had negative aspirates. These data and specimens obtained compared quite favourably with other series in which a modification of the Vim-Silverman needle was used.

The technique of bone marrow aspiration has become universally accepted and widely used. However, the merits of closed needle biopsy are less widely appreciated. Needle biopsy of the posterior iliac crest is easily performed with no morbidity (Ellis, Jensen, and Westerman, 1964). Two large series have been reported using modifications of the Vim-Silverman needle (Ellis, Jensen, and Westerman, 1964; Grann, Pool, and Mayer, 1966) and more recently a series utilizing the Jamshidi-Swaim biopsy needle (Hansen, Muggia, and Selawry, 1971). We have examined 205 consecutive Jamshidi-Swaim marrow biopsies and simultaneous aspirates with respect to the adequacy of specimen, the number of positive biopsies in the various categories of neoplasia, and the disparity between biopsy and aspirate.

\section{Methods}

Bone marrow aspirations and biopsies were made through the same skin incision, but through different areas on the cortical surface of the posterior superior

Please send requests for reprints to James D. Bearden, M.D., Hematology-Oncology Service, Department of Medicine, Wilford Hall USAF Medical Center (AFSC), Lackland AFB, Texas 78236.

Received for publication 30 May 1974. iliac crest. Aspiration was done first with a shortenee 18 gauge spinal needle. Marrow particles, removed from a small amount of the aspirated marrow, were then spread by coverslip pull preparation and stained with Wright stain.

An 11 gauge Jamshidi-Swaim needle was used for biopsies according to the method outlined (Jamshidi and Swaim, 1971). The bone marrow tissue was fixed in formalin for 24 hours, decalcified for two to six hours depending on the size of the specimen, and then processed in a routine fashion before staining. The histological specimens are routinely stained with haematoxylin and eosin. Serial sections or step cuts were routinely examined and increased the yield of positive biopsies.

\section{Results}

Two hundred and five biopsies, accompanied by simultaneous aspirates, were performed with no significant morbidity (table I). Only two of the 205 specimens $(1.0 \%)$ obtained, utilizing the JamshidiSwaim needle for aspiration specimens, were inade-

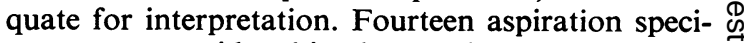
mens were considered inadequate because of packed marrows, myelofibrosis, aplastic marrows, or inadequate quantity. There were virtually no crush arti- 


\begin{tabular}{|c|c|c|c|c|c|c|c|c|c|c|}
\hline \multirow[t]{2}{*}{ Diagnosis } & \multirow{2}{*}{$\begin{array}{l}\text { No. of } \\
\text { Specimens }\end{array}$} & \multirow{2}{*}{$\begin{array}{l}\text { Percentage } \\
\text { Positive } \\
\text { Biopsies }\end{array}$} & \multicolumn{2}{|c|}{ Adequacy of Biopsy } & \multicolumn{2}{|c|}{ Specimen Aspirate } & \multicolumn{2}{|c|}{ Positive Biopsy } & \multicolumn{2}{|c|}{ Negative Biopsy } \\
\hline & & & Adequate & Inadequate & Adequate & Inadequate & $\begin{array}{l}\text { Positive } \\
\text { Aspirate }\end{array}$ & $\begin{array}{l}\text { Negative } \\
\text { Aspirate }\end{array}$ & $\begin{array}{l}\text { Positive } \\
\text { Aspirate }\end{array}$ & $\begin{array}{l}\text { Negative } \\
\text { Aspirate }\end{array}$ \\
\hline $\begin{array}{l}\text { Hodgkin's disease } \\
\text { Malignant lymphoma }\end{array}$ & 62 & $6 \cdot 5$ & 61 & 1 & 57 & 5 & 0 & 4 & $\mathbf{0}$ & 58 \\
\hline Lymphocytic & 23 & 26 & 23 & $\mathbf{0}$ & 23 & $\mathbf{0}$ & 0 & 6 & 1 & 16 \\
\hline Histiocytic & 12 & 17 & 12 & $\mathbf{0}$ & 100 & 23 & $\mathbf{0}$ & 2 & 0 & 10 \\
\hline Lymphocytic-histiocytic & 1 & $\mathbf{0}$ & 1 & $\mathbf{0}$ & 1 & $\mathbf{0}$ & $\mathbf{0}$ & $\mathbf{0}$ & $\mathbf{0}$ & 1 \\
\hline Carcinoma breast & 15 & 67 & 15 & 0 & 13 & 2 & 2 & 8 & $\mathbf{0}$ & 5 \\
\hline Carcinoam bronchogenic & 21 & 5 & 21 & $\mathbf{0}$ & 21 & 0 & $\mathbf{0}$ & 1 & 1 & 19 \\
\hline Melanoma & 8 & $37 \cdot 5$ & 8 & 0 & 8 & 0 & 1 & 2 & 0 & 5 \\
\hline breast, lung, or melanoma & 21 & $9 \cdot 5$ & 20 & 1 & 21 & $\mathbf{0}$ & 2 & $\mathbf{0}$ & $\mathbf{0}$ & 19 \\
\hline $\begin{array}{l}\text { Multiple myeloma } \\
\text { Leukaemia, chronic }\end{array}$ & 1 & 100 & 1 & 0 & 1 & 0 & $\overline{1}$ & $\mathbf{0}$ & 0 & 0 \\
\hline $\begin{array}{l}\text { myelogenous } \\
\text { Leukaemia, chronic }\end{array}$ & 6 & 100 & 6 & 0 & 6 & 0 & 6 & 0 & $\mathbf{0}$ & 0 \\
\hline lymphocytic & 4 & 100 & 4 & 0 & 4 & 0 & 4 & $\mathbf{0}$ & $\mathbf{0}$ & $\mathbf{0}$ \\
\hline Leukaemia, acute & 26 & 92 & 26 & $\mathbf{0}$ & 22 & 4 & 22 & 4 & 0 & $\mathbf{0}$ \\
\hline Myeloproliferative disorder & 4 & 50 & 4 & $\mathbf{0}$ & 3 & 1 & 1 & 1 & 1 & 1 \\
\hline Mycosis fungoides & 1 & 0 & 1 & $\mathbf{0}$ & 1 & 0 & $\mathbf{0}$ & $\mathbf{0}$ & $\mathbf{0}$ & 1 \\
\hline Totals & 205 & 33 & 203 & 2 & 191 & 14 & 39 & 28 & 3 & 135 \\
\hline
\end{tabular}

Table I Comparison of the adequacy and yield of aspirations and biopsies

facts in the biopsies. Out of the 205 simultaneous aspirates and biopsies, there were 67 positive findings with biopsy $(32.7 \%)$ and 42 with aspiration $(20.5 \%)$.

Four of 62 patients with Hodgkin's disease (all stages) had a positive biopsy $(6.5 \%)$. None with clinical stage I or II disease were positive (16 patients). The incidence of positive biopsies in patients with clinical stage III and IV is $8.7 \%$. No marrow aspirates were positive.

Six of 23 patients with malignant lymphoma, lymphocytic type, had a positive biopsy ( $26 \%)$. One patient had a negative biopsy, but had a positive aspirate. Two of 12 patients with histiocytic lymphoma had positive biopsies $(16.7 \%)$. None of the aspirates were positive.

Ten of 15 patients with suspected or confirmed metastatic breast carcinoma were found to have a positive biopsy $(66.6 \%)$. In two of the 10 positive biopsies aspirates were also positive.

One of 21 cases of bronchogenic carcinoma had a positive biopsy and a negative aspirate while one of the cases with a negative biopsy had a positive aspirate. Three of eight patients with melanoma $(37.5 \%)$ had a positive biopsy with one of these having a positive aspirate. Of other carcinomas, two cases, carcinoma of the prostate and laryngeal squamous cell carcinoma, yielded positive biopsies from a contingent of 21 cases $(9.5 \%)$.

Aspiration and biopsy were complementary in diagnosing acute leukaemia, chronic lymphocytic leukaemia, and chronic myelogenous leukaemia. Biopsy was of particular value in patients who had inadequate aspirate specimens (or dry taps) with packed or empty marrows in acute leukaemia.

\section{Discussion}

Our series, utilizing the Jamshidi-Swaim needle, compares favourably with previously reported studies (table II). Ellis et al reported on 253 positive biopsies in $1444(18 \%)$ (Ellis, Jensen, and Westerman, 1964). Similarly, Grann et al found 91 positive biopsies in 238 specimens (37.2\%) (Grann, Pool, Mayer, 1966) and Jamshidi and Swaim made 21 diagnoses from 150 biopsies (14\%).

Rosenberg demonstrated a $9 \%$ incidence of positive biopsies and no positive aspirates in 88 patients with a clinical stage III and IV Hodgkin's disease

\begin{tabular}{llcccc}
\hline Series & Needle & No. of Biopsies Positive & $\begin{array}{l}\text { Positive } \\
\text { Biopsies }\end{array}$ & $\begin{array}{l}\text { Positive } \\
\text { Aspirates }\end{array}$ & $\begin{array}{l}\text { Positive } \\
\text { Aspirates (\%) }\end{array}$ \\
\hline Ellis (1) & Westerman Jensen & 1445 & 253 & 96 & 18 \\
Biopsies
\end{tabular}

Table II Comparison of the present series with previously reported studies of bone marrow aspiration and biopsy 
(Rosenberg, 1971). We found $8.7 \%$ positive biopsies in 46 patients with stage III or IV Hodgkin's disease and no positive aspirates.

The importance of bone marrow biopsy in the staging of non-Hodgkin's lymphoma has been emphasized by Rosenberg who found positive biopsies in $63 \%$ of 75 patients with lymphocytic cellular type (Jones, Rosenberg, and Kaplan, 1972). In our series, six of 23 lymphocytic lymphomas were positive for a $23 \%$ incidence. In contrast, Grann's study of 16 histiocytic lymphomas had one positive biopsy $(6 \%)$ and no positive aspirates. In our patients, two of 12 patients with histiocytic lymphoma had positive biopsies $(17 \%)$ with no positive aspirates.

The high yield of positive biopsies in metastatic breast carcinoma in the present series led to earlier recognition of disseminated disease as did the finding of the positive biopsies in melanoma. Our series gives a smaller yield of positive biopsies than the 14 of 100 consecutive biopsies found by Hansen et al in their evaluation of unresectable lung tumours in comparable patients (Hansen, Muggia, and Selawry, 1971). One of our 21 cases of bronchogenic carcinoma had a positive biopsy ( $5 \%$ ).
Bone marrow biopsy is not necessarily a substi- $\frac{0}{+}$ tute for examination of the marrow by aspiration $\underline{\underline{0}}$ and smear, but is an advantageous complementary $\vec{\Rightarrow}$ procedure. Larger amounts of marrow can be ex- $\stackrel{\oplus}{+}$ amined, cellularity readily assessed, architectural patterns analyzed, and structures other than haematopoietic cells examined. Aspiration is the most effective way of studying cellular morphology.

The combined procedures of aspiration and biopsy $\approx$ give a higher yield and are essential in patients with suspected carcinoma, non-Hodgkin's lymphoma, and Hodgkin's disease.

References

Ellis, L. D., Jensen, W. N., and Westerman, M. P. (1964). Needle biopsy of bone marrow. Arch. intern. Med., 14, 213-221.

Grann, V., Pool, J. L., and Mayer, K. (1966). Comparative study of bone marrow aspiration and biopsy in patients with neoplastic disease. Cancer (Philad.), 19, 1898-1900.

Hansen, H. H., Muggia, F. M., and Selawry, O. S. (1971). Bone marrow examination in 100 consecutive patients with bronchogenic carcinoma. Lancet, 2, 443-445.

Jamshidi, K., and Swaim, W. R. (1971). Bone marrow biopsy with $\mathcal{S}$ unaltered architecture: a new biopsy device. J. Lab. clin. Med., 77, 335-342.

Jones, S. E., Rosenberg, S. A., and Kaplan, H. S. (1972). NonHodgkin's lymphomas I. Bone marrow involvement. Cancer (Philad.), 29, 954-960.

Rosenberg, S. A. (1971). Hodgkin's disease of the bone marrow Cancer Res., 31, 1733-1736. 